\title{
CONSTRUCTING RESILIENCE MODEL OF PORT INFRASTRUCTURE BASED ON SYSTEM DYNAMICS
}

\author{
HYUNGMIN CHO \& HEEKYUNG PARK \\ Department of Civil and Environmental Engineering, KAIST, Republic of Korea.
}

\begin{abstract}
The port industry, which plays an important role in Korea's economy, is exposed to various disasters such as earthquakes, tsunamis, and chemical accidents. Therefore, resilience needs to be assessed to evaluate how properly port system can recover its function even after being damaged, and weak points should be complemented by the policy. However, the port infrastructure is too complicated to analyze all the components, so a systemic approach is needed. Therefore, this study evaluates the resilience of the port infrastructure using system dynamics model, which can compare quantitative performance index. This study sets up the cargo process, the most important economic index of the port, as the performance level and constructs a system dynamics model by finding elements corresponding to attributes of resilience. In addition to disruption and recovery actions in the disaster situation, the model also incorporates socioeconomic factors such as changes in cargo demand and financial state, resulting in close proximity to case studies. Simulation of disaster situations with resilience assessment model can express recovery process of the system and accumulated economic damage. By applying various inputs and scenarios, the result of this study can be used as a basis for comparing the resilience of port infrastructure and establishing the reinforcement policy.

Keywords: infrastructure resilience, port disaster, system dynamics model
\end{abstract}

\section{INTRODUCTION}

In South Korea, port industry is one of the nation's most important industries because economy of South Korea heavily relies on international trade compared to other developed countries [1] and $99 \%$ of trade freights pass through maritime transportation [2]. In September 2003, typhoon Maemi, which recorded the strongest wind speed in South Korea, caused large damage to south-eastern part of Korea including Busan port. As South Korea confronted serious disruption in maritime transportation and rapid recovery was demanded, it reminded importance of resilience against natural disaster in major ports. In near countries, Hanshin earthquake in 1995 and Tianjin explosions in 2015 were also recorded as severe accidents that damaged major national ports and paralyzed logistics [3, 4]. Likewise, in Korea, risk of earthquake and chemical accidents along industrial areas in coastal regions has been pointed out $[5,6]$. In other words, it can be said that major ports in South Korea also have been exposed to various hazards. These recent environments increase necessity of making mitigation policies to port infrastructure system in South Korea. As a first step, port infrastructures need to be evaluated for their current resilience capacity. This study looks at the features of port infrastructure in view of resilience and then discusses method to measure the resilience of port functions.

\section{BACKGROUND}

\subsection{Infrastructure resilience}

In recent years, series of disasters revealed vulnerability of infrastructure systems and hence improving resilience of infrastructure became important strategy to reduce the risk [7]. 
Although concepts of resilience applied to port are various in meaning and range [8], one of the agreed definitions in disaster studies is that 'ability of system to resist, absorb, accommodate and recover from hazard' [9]. With this definition, ways of measuring resilience used in previous studies are categorized to qualitative and quantitative methods [10]. Quantification investigates total impact of disruptive event to performance level of system [11, 12] or total amount of recovery effort of system from given damage [13]. Bruneau et al. [11] also suggested attributes of resilience; Robustness, Redundancy, Resourcefulness and Rapidity. As end-attributes, meaning of robustness and rapidity of resilience with performance level is shown in Figure 1. This also implies that two attributes of resilience are distinguished by before or after event [14]. Furthermore, Francis and Bekera [15] proposed adaptive capacity in addition to absorptive and restorative capacity, which refers improvement of performance level after event. However, this improvement in infrastructure system is achieved by getting new facilities from external investment in contrast with self-organizing ecosystem.

\subsection{Port-related disasters}

In law of Korea, definition of port, or harbour, covers from seaway, anchorage, all facilities related to function to hinterland. So most of accidents in port area are crashes, construction accidents, fire, blackout, and safety accidents and they do not have significant impact on function of the port. However, typhoon Maemi damaged 11 container cranes reducing 24\% of unloading capacity of Busan port [16]. These cases imply that measuring performance decline needs to focus on huge disaster rather than the minor operational failure. Labor strike is also reported as major cause of port disability as well as natural disaster [17], but this study excludes those kinds of social problems because affecting factors are too uncertain to be included in infrastructure system model.

One of the well-known cases of port related disaster is Hanshin earthquake and Kobe port, Japan in 1995. Chang [3] investigated loss of Kobe port after earthquake with comparing competing ports in Japan and abroad. Massive earthquake damaged most of berths and container cranes so market share of Kobe port fell sharply after January, 1995. However, more important implication is that Kobe port could not fully recover its previous market

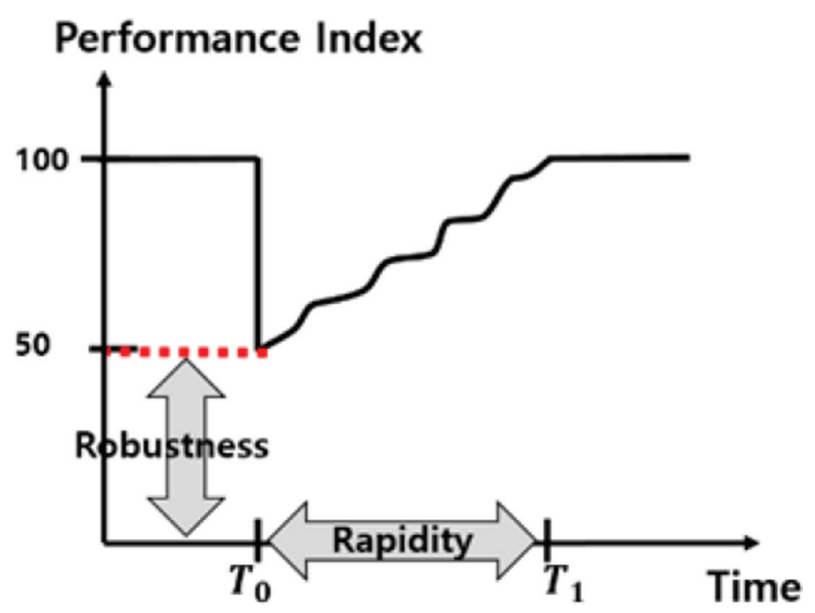

Figure 1: Resilience quantification and attributes (Source: Tierney \& Bruneau, 2007). 
share in line with the facility recovery (Fig. 2). Chang [3] explained this long-term loss with reason that smaller ports of Japan took away market shares without transhipment in Kobe in domestic market. Also, International market share moved to other Asian ports such as Kaohsiung and Busan. This long-term impact is caused by the characteristics of maritime logistics, which has interdependent supply chains and disruption results in shift of customers $[18,19]$.

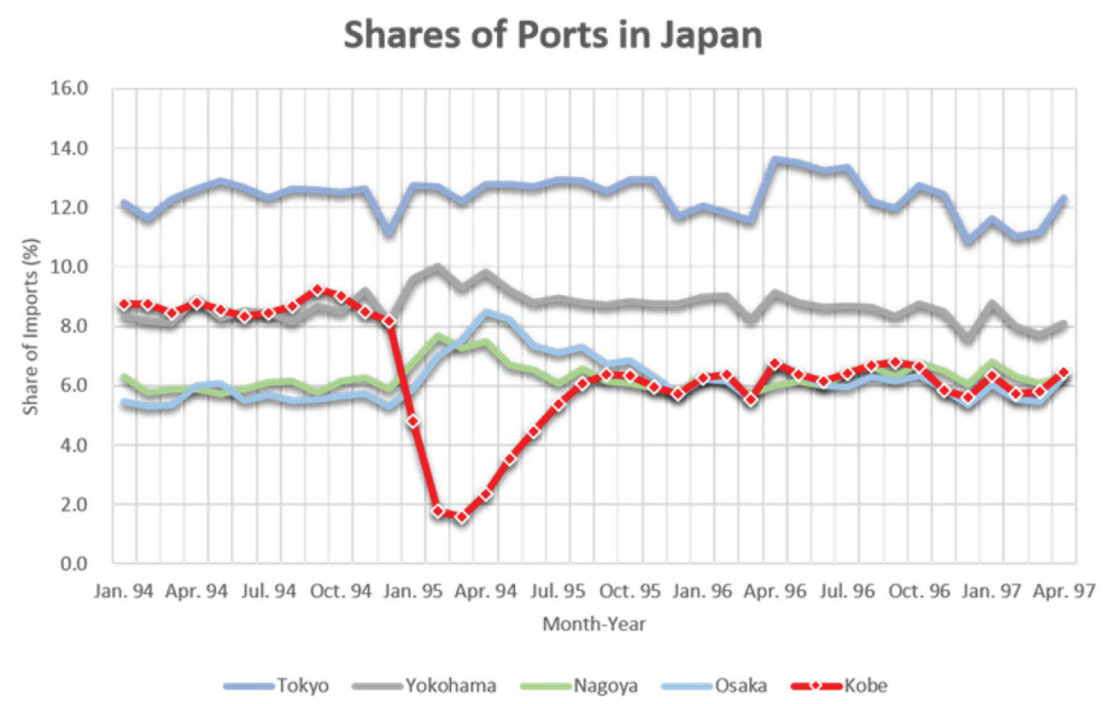

(a)

Shares of Ports in Asia

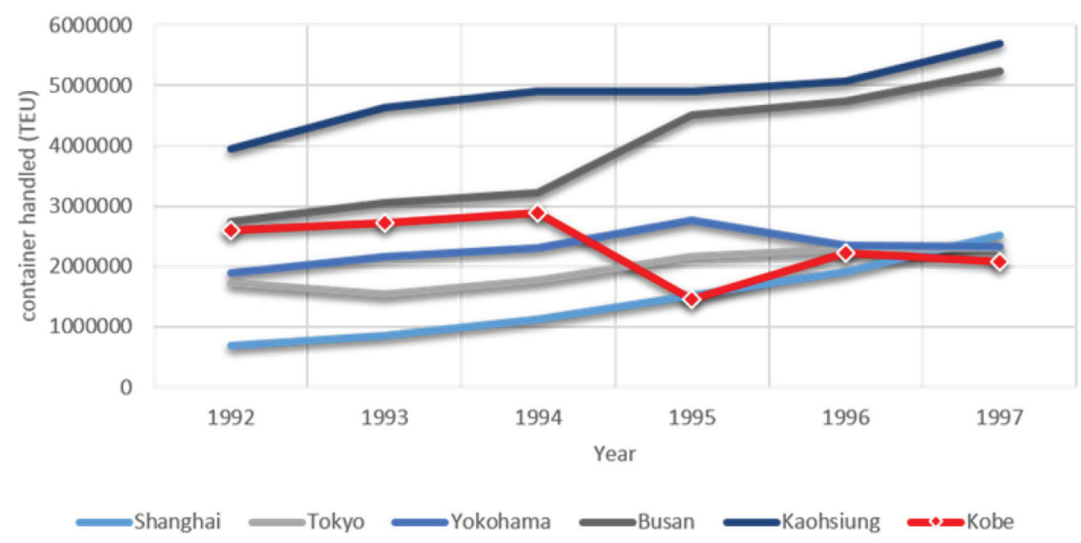

(b)

Figure 2: Changes in market shares of ports before and after the Hanshin earthquake (a) in Japan; (b) in Asia (Source: Chang, 2000). 


\subsection{System dynamics}

System dynamics model is a widely used method to represent complex and nonlinear structures and phenomenon [20]. It has been used to investigate the infrastructure system [21] and maritime transportation system [22]. As system dynamics method focuses on how specific variable changes over time [23], it is usable to assess performance of infrastructure system over time after disaster occurs. By previous studies, system dynamics have been applied to maritime transportation as critical infrastructure for measuring post-disaster state and managing it [24-27] but they focused on transportation system not port infrastructures carefully.

\section{CONSTRUCT RESILIENCE MODEL OF PORT INFRASTRUCTURE}

\subsection{Conceptual framework}

This study constructs resilience model with two features; assessing performance level and system dynamics analysis using STELLA. Performance level of system should be determined to indicate generally required performance of port system. In previous studies, amount of handled cargo is suggested to measure the port performance in terms of the number of containers [28] or tonnage [29]. Our model sets the performance level as amount of processed cargo per time while assuming a virtual unit has limitation in analysis. A simple feedback loop of system dynamics model which can be applied to any type of disaster is suggested in Figure 3. Positive impact is indicated by blue arrow with label $\mathrm{p}$, and negative impact is indicated by red arrow with label $\mathrm{n}$. Since the key of system dynamics is creating feedback loop which makes nonlinear change [23], it is needed to construct appropriate feedback loop on port infrastructure system in this study. In Figure 3, total loop becomes negative feedback loop which means that disruption is mitigated as decreased performance enhances recovery activity. Consequently, capacity of infrastructure system is restored and performance level returns to normal condition over time as shown in Figure 4.

In model of this study, disaster and disruption are given input value by disaster scenario. Then, other components; capacity of facilities, performance level and recovery activity are able to be affected by external factors. Those variables are derived from literature review and categorized to robustness and rapidity (see Table 1). For variables of robustness, Kim et al. [2] studied response to disruption in terms of BCM (Business Continuity Management) which focuses on continuing to provide port service. In this view, damaged service is not same as total physical loss as long as service is available. Therefore, suggested major factors of BCM in port are internal redundant capacity and replaceable level by neighboring ports. This strategy to replace traffic at undamaged facilities is known to be effective in reducing economic loss [30].

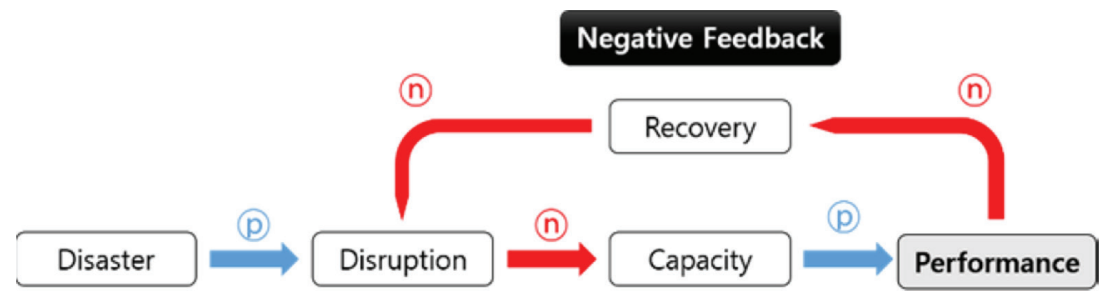

Figure 3: Basic system dynamics model and feedback loop. 


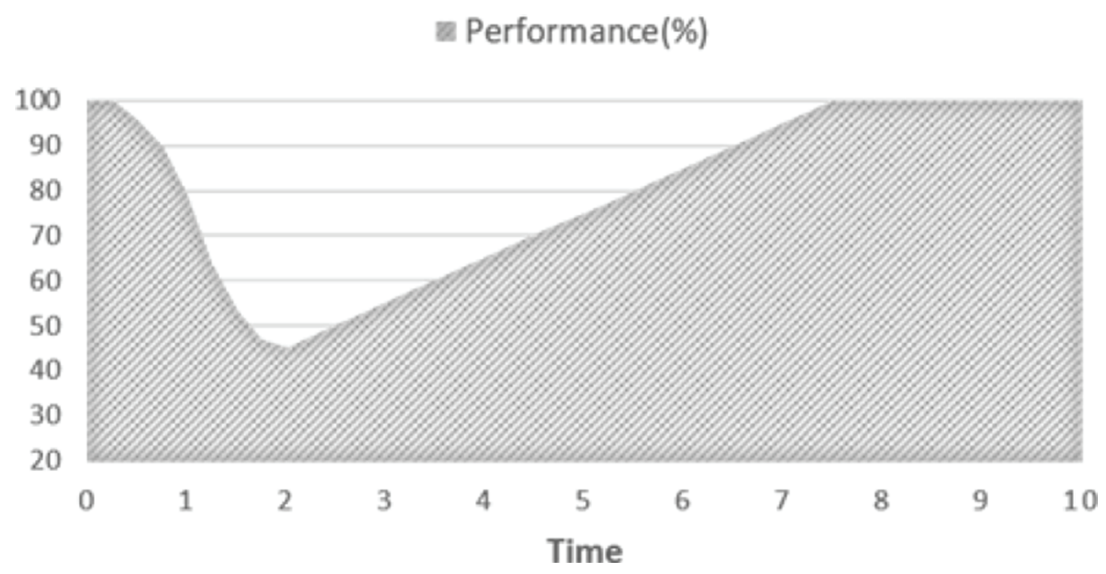

Figure 4: Performance graph of basic model.

Table 1: Attribute and variables of resilience model.

\begin{tabular}{lll}
\hline Attributes & Variables & Source \\
\hline Performance level & Capability of processing cargo & {$[29]$} \\
Robustness & Allowance capacity & {$[2]$} \\
& Replaceable nearby ports & \\
& Failure ratio & {$[31]$} \\
Rapidity & Repair ratio & {$[27,31]$} \\
& Time to repair & \\
\hline
\end{tabular}

Among identified variables in Table 1, allowance capacity, replaceability and resource for repair have positive effect to system components as seen in Figure 5. Figure 6 shows effect of improvement of robustness and rapidity to reducing maximum damage or recovery time. However, system with more rapid recovery, marked in yellow line, got less drop of performance than black line. This is because recovery activity begins as disruption starts to reduce performance level. This feature of system dynamics does not correspond to expected effect of rapidity. Nevertheless, it is still reasonable when disruption in scenario lasts for some time, while some disaster such as earthquake occurs in very short time.

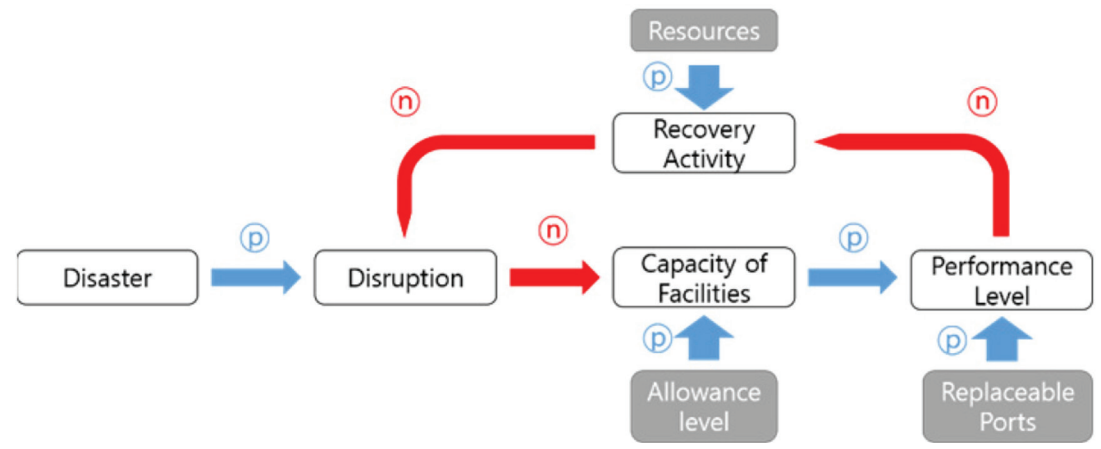

Figure 5: System dynamics model with resilience variables. 


\section{Comparision of Resilience Attributes}

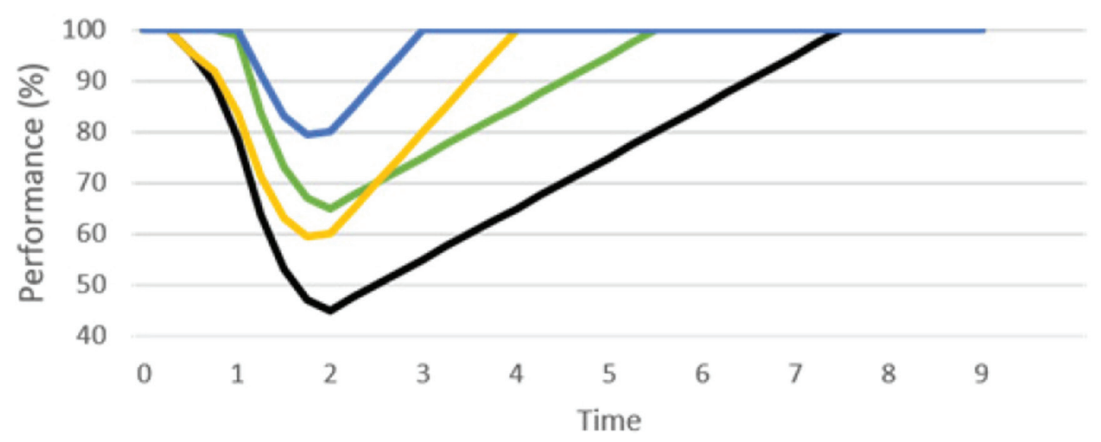

Default $\longrightarrow$ Robust Rapid $\longrightarrow$ Both

Figure 6: Comparison of performance among different resilience attributes.

\subsection{Long-term loss and delayed recovery}

As case of Kobe port in Figure 2 shows importance of considering long-term loss, advanced model needs additional long-term elements. Again, components which affect performance level after recovery are related to consumers' choice of port [3]. The major determinants for customers to choose a port are known as the cost and time of using it $[28,32,33]$. On the other hands, Lee [34] pointed out that there is no big difference in cost and facilities among major ports so marketing affects to amount of cargo in meaningful level. When these determinants of port weaken, it can be said that trade volume would be transferred to other ports as seen in Kobe port case [3, 35].

Using STELLA, resilience model including disruption, recovery and long-term effect is constructed (Fig. 7). Looking the bottom loop of Figure 7, cargoes in disabled system are assumed to be moved to other port during disruption and recovery stage. This happens because waiting for recovery increases time and cost for shipping. Moved demands reduce the attractiveness of the port because it takes additional time and cost in returning to original port. However, this long-term loss is not defined as irreparable damage. On the assumption that stabilized financial state of port can create motivating actions such as incentive or advanced facility, attractiveness and performance level recover over time gradually. Financial state of port is assumed to be affected by recovery cost and benefit from cargo process. In long-term loss model, resilience attributes discussed in Figures 5 and 6 are assumed to be constant value that does not affect to result significantly and marked with grey boxes.

Result of long-term loss model is shown in Figure 8. Long-term loss due to reduced attractiveness appears after 20 time units. That is when delayed transportation is processed and facilities are fully repaired but incoming cargoes decrease. As financial state recovers after lowest point, attractiveness and performance of port also recover slowly. Slopes of recovery seem too gentle, but it is reasonable considering disasters such as earthquake and typhoon happens from few hours to days. Furthermore, some factors which can affect financial state and recovery rate are excluded in model since external aids are beyond our model boundary. 


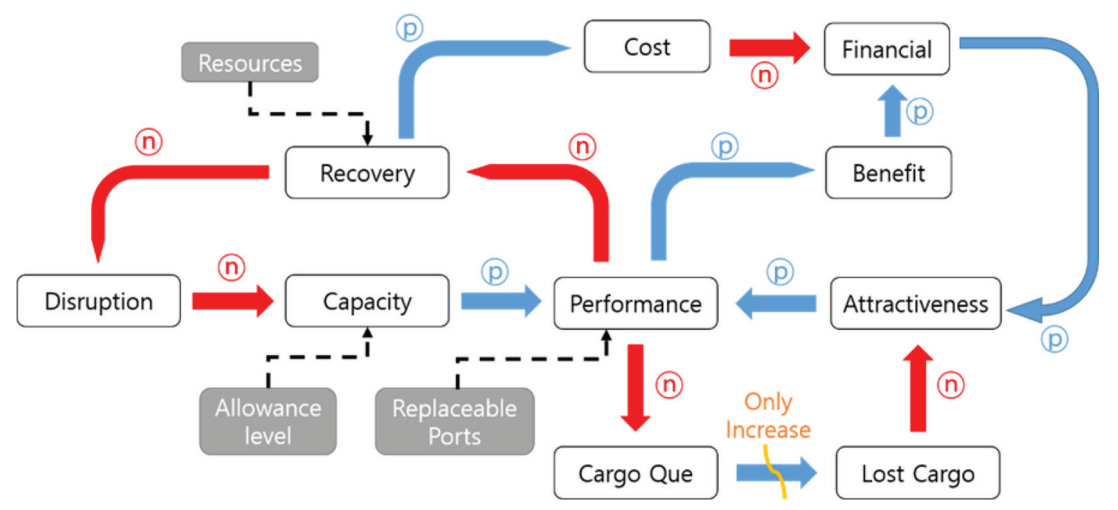

Figure 7: System dynamics model with long-term loss.

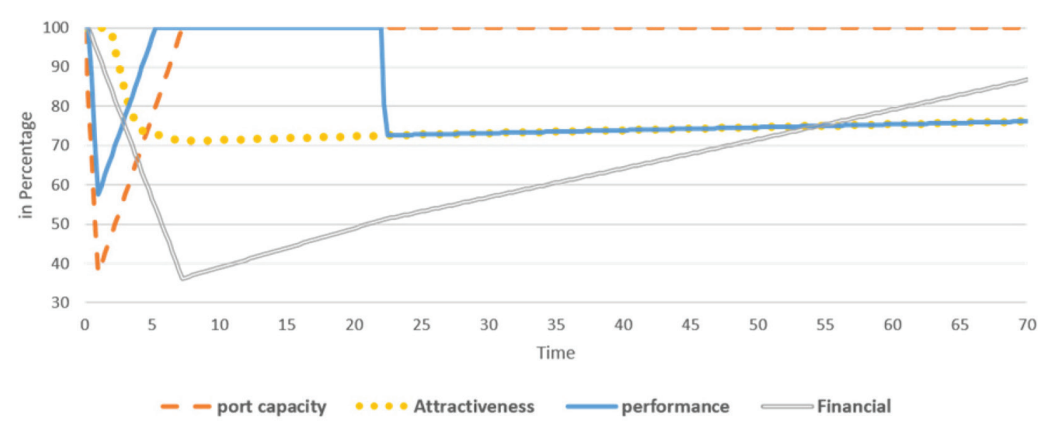

Figure 8: Result of long-term loss model.

\section{CONCLUSION}

Starting from the need for measurement of resilience to port disasters, we reviewed the related theoretical background and constructed resilience model using system dynamics with STELLA. Although port system is highly complex with numerous number of elements, system dynamics model could show brief conceptual model and approximate measurement of resilience. This study could not apply constructed model to actual site or disaster records due to lack of the detailed settings in model. This study conceptualizes the resilience of port infrastructure system and identifies possibility of using the system dynamics model. It is expected that further studies will be able to construct more detailed model and continue research to measure resilience of port infrastructure system.

\section{ACKNOWLEDGEMENTS}

This research was supported by a grant [MPSS-CG-2015-01] through the Disaster and Safety Management Institute funded by Ministry of Public Safety and Security of Korean government.

\section{REFERENCES}

[1] OECD, Factbook 2011: Economic, Environmental and Social Statistics, 2011.

[2] Kim, H., Lee, J., Ha, T. \& Lee, J., A Study on Impacts of Port Accidents \& Disasters and Responsive Measures. Korea Maritime Institute: Seoul, 2012. 
[3] Chang, S.E., Disasters and transport systems: loss, recovery and competition at the Port of Kobe after the 1995 earthquake. Journal of Transport Geography, 8(1), pp. 53-65, 2000.

https://doi.org/10.1016/s0966-6923(99)00023-x

[4] Chung, Y. \& Kim, H., On the August 12, 2015 occurrence of explosions and fires in Tianjin, China, and the atmospheric impact observed in central Korea. Air Quality, Atmosphere \& Health, 8(6), pp. 521-532, 2015.

https://doi.org/10.1007/s11869-015-0371-2

[5] Kim, M., Seismic damage and prevention of ports. Facility Safety Magazine, p. 12, 2003.

[6] Choi, S.-D., Suggestion for Ulsan that is safe from chemical accidents. Ulsan Development, 40, pp. 28-39, 2013.

[7] Chang, S.E., Infrastructure resilience to disasters. The Bridge, 44(3), 2014.

[8] Cao, M., Transportation Resilience: A summative review on Definition and Connotation. International Conference on Automation, Mechanical Control and Computational Engineering, 2015.

[9] UNISDR, UNISDR Terminology on Disaster Risk Reduction. United Nations: Geneva, 2009.

[10] Hosseini, S., Barker, K. \& Ramirez-Marquez, J.E., A review of definitions and measures of system resilience. Reliability Engineering \& System Safety, 145, pp. 47-61, 2016. https://doi.org/10.1016/j.ress.2015.08.006

[11] Bruneau, M., Chang, S.E., Eguchi, R.T., Lee, G.C., O'Rourke, T.D., Reinhorn, A.M., Shinozuka, M., Tierney, K., Wallace, W.A. \& von Winterfeldt, D., A framework to quantitatively assess and enhance the seismic resilience of communities. Earthquake Spectra, 19(4), pp. 733-752, 2003. https://doi.org/10.1193/1.1623497

[12] Tierney, K. \& Bruneau, M., Conceptualizing and measuring resilience: A key to disaster loss reduction. TR news, 250, pp. 14-17, 2007.

[13] Vugrin, E.D., Warren, D.E., Ehlen, M.A. \& Camphouse, R.C., A framework for assessing the resilience of infrastructure and economic systems. Sustainable and resilient critical infrastructure systems, Springer: Berlin, pp. 77-116, 2010.

[14] McDaniels, T., Chang, S., Cole, D., Mikawoz, J. \& Longstaff, H., Fostering resilience to extreme events within infrastructure systems: characterizing decision contexts for mitigation and adaptation. Global Environmental Change, 18(2), pp. 310-318, 2008.

[15] Francis, R. \& Bekera, B., A metric and frameworks for resilience analysis of engineered and infrastructure systems. Reliability Engineering \& System Safety, 121, pp. 90-103, 2014.

[16] YGPA, Disaster Cases in Port. Yeosu Gwangyang Port Authority: Yeosu, 2016.

[17] Lam, J.S.L. \& Su, S., Disruption risks and mitigation strategies: an analysis of Asian ports. Maritime Policy \& Management, 42(5), pp. 415-435, 2015.

[18] Lam, JSL., Risk management in maritime logistics and supply chains. Maritime Logistics: Contemporary Issues, Emerald Group Publishing Limited, pp. 117-132, 2012.

[19] Sheffi, Y. \& Rice, Jr, J.B., A supply chain view of the resilient enterprise. MIT Sloan Management Review, 47(1), p. 41, 2005.

[20] Forrester, J.W., System dynamics, systems thinking, and soft OR. System Dynamics Review, 10(2-3), pp. 245-256, 1994.

[21] Ouyang, M., Review on modeling and simulation of interdependent critical infrastructure systems. Reliability Engineering \& System Safety, 121, pp. 43-60, 2014. 
[22] Oztanriseven, F., Pérez-Lespier, L., Long, S. \& Nachtmann, H., A review of system dynamics in maritime transportation. IIE Annual Conference Proceedings, p. 2447, 2014.

[23] Yoon, Y.S. \& Chae, S.B., Introduction to complex systems. SERI: Seoul, 2005.

[24] Lespier, LP. A systems thinking approach to post-disaster restoration of maritime transportation systems. IIE Annual Conference Proceedings, 2015.

[25] Mansouri, M., Nilchiani, R. \& Mostashari, A., A risk management-based decision analysis framework for resilience in maritime infrastructure and transportation systems. Systems Conference, 2009 3rd Annual IEEE, 2009.

[26] Mansouri, M., Sauser, B. \& Boardman, J., Applications of systems thinking for resilience study in maritime transportation system of systems. Systems Conference, 2009 3rd Annual IEEE, 2009.

[27] Croope, S. \& McNeil, S., Improving resilience of critical infrastructure systems postdisaster: recovery and mitigation. Transportation Research Record: Journal of the Transportation Research Board, 2234, pp. 3-13, 2011.

[28] Tongzon, J.L., Determinants of port performance and efficiency. Transportation Research Part A: Policy and Practice, 29(3), pp. 245-252, 1995.

[29] Omer, M., Mostashari, A., Nilchiani, R. \& Mansouri, M., A framework for assessing resiliency of maritime transportation systems. Maritime Policy \& Management, 39(7), pp. 685-703, 2012.

[30] Pachakis, D. \& Kiremidjian, A.S., The use of simulation in disaster response planning and risk management of ports and harbors. Advancing Mitigation Technologies and Disaster Response for Lifeline Systems, pp. 425-434, 2004. https://doi.org/10.1061/40687(2003)44

[31] Laugé, A., Hernantes, J. \& Sarriegi, J.M., The role of critical infrastructures' interdependencies on the impacts caused by natural disasters. International Workshop on Critical Information Infrastructures Security, pp. 50-61, 2013.

[32] Park, N-K., Moon, D. \& Lim, C-K., Port choice model of Transhipment cargo using system dynamics. Maritime Logistics, Emerald Group Publishing Limited, pp. 69-90, 2012.

[33] Yeo, G-T., Pak, J-Y. \& Yang, Z., Analysis of dynamic effects on seaports adopting port security policy. Transportation Research Part A: Policy and Practice, 49, pp. 285-301, 2013. https://doi.org/10.1016/j.tra.2013.01.039

[34] Lee, H., Factors affecting port competitiveness. Korean Public Administration Quarterly, 24(1), pp. 1-25, 2012.

[35] Achurra-Gonzalez, P.E., Novati, M., Foulser-Piggott, R., Graham, D.J., Bowman, G., Bell, M.G.H. \& Angeloudis, P., Modelling the impact of liner shipping network perturbations on container cargo routing: Southeast Asia to Europe application. Accident Analysis \& Prevention, 2016. 